CGBQ liên quan đến tổn thương thân. Điều này có thể giải thích khi mà giảm độ CGBQ sẽ dẫn tới thay đổi $A L B Q$ cao là yếu tố nguy cơ gây tổn thương thận.

\section{KẾT LUẬN}

Sẹo thận liên quan đến chức năng bàng quang với giảm độ co giãn bàng quang, thể tích bàng quang so với tuổi $<65 \%$ và áp lực bàng quang $\geq 30 \mathrm{cmH}_{2} \mathrm{O}$, ở bệnh nhân sau mổ dị tật nứt đốt sống bẩm sinh.

TÀI LIÊU THAM KHẢO

1. Ginsberg D (2013). The Epidemiology and Pathophysiology. Am J Manag Care, 19, 191-196.

2. Bauer S.B (2008). Neurogenic bladder: etiology and assessment. Pediatr Nephrol, 23(4), 541-51.

3. Dik P, Klijn A.J, Van Gool J.D et al (2006). Early start to therapy preserves kidney function in spina bifida patients. Eur Urol, 49(5), 908-13.

4. Ozel S.K, Dokumcu Z, Akyildiz $C$ et al ( 2007). Factors affecting renal scar development in children with spina bifida. Urol Int, 79(2), 133-6.

5. Shiroyanagi $Y$, Suzuki $M$, Matsuno $D$ et al ( 2009). The significance of 99mtechnetium dimercapto-succinic acid renal scan in children with spina bifida during long-term followup. J Urol, 181(5), 2262-6; discussion 2266.

6. Arora G, Narasimhan K.L, Saxena A.K et al (2006). Risk Factors for Renal Injury in Patients with Meningomyelocele. Indian Pediatrics, 44, 417-420.

7. Prakash $R$, Puri A, Anand $R$ et al (2017). Predictors of upper tract damage in pediatric neurogenic bladder. J Pediatr Urol, 13(5), 503 e1-503 e7.

8. Bruschini $H$, Almeida F.G, Srougi $M$ et al (2006). Upper and lower urinary tract evaluation of 104 patients with myelomeningocele without adequate urological management. World J Urol, 24(2), 224-8.

\title{
KẾT QUẢ PHẪU THUÂTT KHÂU KÍN ỐNG MÂTT CHỦ SAU KHI LẤY SỎI ĐỂ ĐIỀU TRİ SỎI ĐƯờNG MÂTT CHÍNH NGOÀI GAN TẠI BỆNH VIỆN BẠCH MAI
}

\section{TÓM TẮT}

Mục tiêu: Kết quả của phương pháp khâu kín ông mật chủ sau khi lấy sỏi để điều trị sỏi đường mật chính ngoài gan. Đối tượng và phương pháp nghiên cứu: Mô tả hồi cứu 70 bệnh nhân được phẫu thuật mở bụng, mở ống mật chủ lấy sỏi và khẩu kín OMC ngay tai Khoa Ngoai Bểnh viên Bach Mai từ 2014 đến 2020. Kết quả: 70 trường hợp trong nghiên cứu bao gồm 42 nữ và 28 nam, tuổi trung bình là 62 $\pm 15,2$ tuổi, 34 trường hợp $(48,5 \%)$ có tiền sử mổ sỏi mật, thời gian nằm viện sau mổ là $7,91 \pm 2,07$ ngày, không có tử vong sau mổ, tỉ lệ biến chứng chung là $10,0 \%$ trong đó tụ dịch dưới gan là chủ yếu $5,7 \%$, Kết luận: phẫu thuật khâu kín ống mật chủ sau khi lấy sỏi an toàn, hiệu quả. Chỉ định cho các trường hợp lây hết sỏi ống mật chủ, không có sỏi trong gan, cơ Oddi thông tốt, dịch mật trong sach.

Tư khóa: Sỏi ống mật chủ; khâu kín ống mật chủ

\section{SUMMARY}

PRIMARY CLOSUSE COMMON BILE DUCT AFTER REMOVER STONE AT BACH MAI HOSPITAL

Aims: Objective: The results of primary closure after remover stones for the treatment of common bile duct (CBD) stone. Matarial and Methods: A

*Bệnh viện Bạch Mai

Chịu trách nhiệm chính: Trân Mạnh Hùng

Email: tranmanhhungngoaibm@gmail.com

Ngày nhận bài: 2.01.2021

Ngày phản biên khoa học: 25.2.2021

Ngày duyệt bài: 10.3.2021 retrospective study of 70 patients with open abdominal surgery, common bile duct exploration for removal stones and primry closure CBD at Bach Mai Hospital from 2014 to 2020. Results: 70 cases in the study included 42 females and 28 males, mean age 62 \pm 15.2 years, 34 cases $(48.5 \%)$ had CBD stones recurent, postoperative hospital stay was $7.91 \pm 2.07$ days, there was no postoperative mortality, complication rate was $10.0 \%$, in which the hepatic fluid was $5.7 \%$. Conclusion: Primary closure common bile duct after removal stones is safe and effective

Key word: primary closure common bile duct; common bile duct stone

\section{I. ĐĂT VẤN ĐỀ}

Phẫu thuật mở bụng, mở ống mật chủ (OMC) lấy sỏi vẫn là phương pháp chủ yểu trong điêu trị sỏi đường mật chính với các trường hợp có chống chỉ định hoặc không thực hiện được bằng phẫu thuật nội soi (PTNS). Khi mở ống mật chủ lấy sỏi, dẫn lưu Kehr được sử dụng. Mục đích của dẫn lưu Kehr là giảm áp đường mật, dẫn lưu dịch mật nhiễm trùng, tạo ra đường vào để lấy sỏi còn sót lại. Khi các vấn đề trên được giải quyết thì không nhất thiết phải đặt ống dẫn lưu Kehr. Tại khoa Ngoại Bệnh viện Bạch Mai chúng tôi đã tiến hành khâu kín ống mật chủ sau khi lấy sỏi để điêu trị sỏi đường mật chính ngoài gan trong phẫu thuật mở cho nhiều trường hợp đạt kết quả tốt. Nghiên cứu này nhằm mưc tiêu: Đánh giá kết quả của phương pháp phẫu thuật 
khâu kín ông mật chủ sau khi lấy sỏi để điều trị sỏi đường mật chính ngoài gan

II. ĐỐI TƯợNG VÀ PHƯƠNG PHÁP NGHIÊN CỨU

1. Đối tượng nghiên cứu.

- Tiêu chuẩn chọn bệnh nhân.

- Tất cả các trường hợp(TH) đều được chụp cộng hưởng từ dựng hình đường mật trước mổ

- Được chẩn đoán sỏi đường mật chính ngoài gan, có hoặc không kèm theo sỏi túi mật.

- Bệnh nhân được mổ có kễ hoạch mở bụng, lấy sỏi đường mật chính ngoài gan và khâu kín OMC ngay

- Tiêu chuẩn loại trừ.

- Loại khỏi nghiên cứu các trường hợp có sỏi trong gan kèm theo, hẹp bất kỳ vị trí nào của đường mật

2.Phương pháp nghiên cứu. Mô tả hồi cứu 70 bệnh nhân được phẫu thuật mở bụng, mở ống mật chủ lấy sỏi và khâu kín OMC ngay tại Khoa Ngoại Bệnh viện Bạch Mai từ 2014 đển 2020.

\section{KẾT QUẢ NGHIÊN CỨU}

70 trường hợp sỏi đường mật chính ngoài gan trong đó có 42 nữ và 28 nam, tuổi thấp nhất 27, cao nhất 82 tuổi; tiền sử mổ sỏi mật 1 lần là 26 trường hợp $(37,1 \%)$, mổ sỏi mật 2 lần 8 trường hợp $(11,4 \%)$.

Bảng 3.1. Triệu chứng lâm sàng khi nhập viện của nhóm nghiên cứu

\begin{tabular}{|c|c|c|}
\hline Triệu chứng lâm sàng & $\mathbf{n}$ & Tỷ lệ (\%) \\
\hline Đau hạ sườn $\mathrm{P}$ & 68 & 97,1 \\
\hline Sốt $\geq 37,5$ & 25 & 35,7 \\
\hline Vàng da & 27 & 38,6 \\
\hline Gan to & 12 & 17,1 \\
\hline Túi mật to & 9 & 12,8 \\
\hline Phản ứng dưới sườn $\mathrm{P}$ & 11 & 15,7 \\
\hline
\end{tabular}

Nhận xét: Hầu hết các BN đều có đau ha sườn phải khi nhập viện $(97,1 \%)$, Các triệu chứng sốt, vàng da chiếm tỉ lệ thấp hơn so với đau hạ sườn phải., Các BN có đầy đủ tam chứng Charcot là $25 \mathrm{TH}(35,7 \%)$.

Bảng 3.2. Kêt quả xét nghiệm huyết học \begin{tabular}{|l|l|l|}
\hline Xét nghiệm huyết học & $\mathbf{n}$ & Tỷ lệ (\%) \\
\hline
\end{tabular}

\begin{tabular}{|c|c|c|c|}
\hline Hồng & $\mathrm{HC}<3,5$ & 1 & 1,4 \\
\cline { 2 - 4 } cầu(T/L) & $\mathrm{HC} \geq 3,5$ & 69 & 98,6 \\
\hline \multirow{3}{*}{$\begin{array}{c}\text { Bà̀ } \\
\text { cầu } \\
(\mathrm{G} / \mathrm{I})\end{array}$} & $\mathrm{BC} \leq 10$ & 41 & 58,6 \\
\cline { 2 - 4 } & $10<\mathrm{BC}<15$ & 23 & 32,8 \\
\cline { 2 - 4 } & $\mathrm{BC} \geq 15$ & 06 & 8,6 \\
\hline
\end{tabular}

Nhân xét: 29TH $(41,4 \%)$ có bạch cầu > $10,0 \mathrm{G} / \mathrm{L}$ trong đó $6 \mathrm{TH}(8,6 \%)$ có bạch câu $\geq 15,0 \mathrm{G} / \mathrm{L}$

Bảng 3.3. Kêt quả xét nghiệm sinh hoá máu \begin{tabular}{|l|l|l|l|l|}
\hline Loại xét & Số TH & Giá trị & Khoảng \\
\hline
\end{tabular}

\begin{tabular}{|c|c|c|c|}
\hline nghiệm & tăng & $\begin{array}{c}\text { trung } \\
\text { bình }\end{array}$ & giá trị \\
\hline $\begin{array}{c}\text { SGOT (U/L) > } \\
40\end{array}$ & $28(40,0)$ & 85,5 & $15-290$ \\
\hline $\begin{array}{c}\text { SGPT (U/L) } \\
>40\end{array}$ & $31(44,3)$ & 118,3 & $6-458$ \\
\hline $\begin{array}{c}\text { Amylaza (U/L) } \\
>100\end{array}$ & $12(17,1)$ & 151,7 & $34-468$ \\
\hline $\begin{array}{c}\text { Bilirubin. TP } \\
(\mu \mathrm{mol} / \mathrm{l})\end{array}$ & $49(70,0)$ & 34,4 & $7,7-140$ \\
\hline
\end{tabular}

Nhận xét: Đa số các TH $(70,0 \%)$ có bilirubin máu tăng

Bảng 3.4. Vị trí và kích thước sỏi OMC trên chụp cộng hưởng từ đường mật

\begin{tabular}{|c|c|c|}
\hline Vị trí sỏi Kích thước sỏi & $20 \mathrm{~mm}$ & $\begin{array}{c}\geq \\
20 \mathrm{~mm}\end{array}$ \\
\hline Sỏi OMC đơn thuần & 4 & 43 \\
\hline Sỏi OMC + sỏi TM & 7 & 16 \\
\hline Tống & 11 & 59 \\
\hline
\end{tabular}

Nhận xét: 20 TH (28\%) có sỏi túi mật kèm theo, 59 TH (84\%) có kích thước sỏi $\geq 20 \mathrm{~mm}$

Bảng 3.5. Chỉ định phẫu thuật

\begin{tabular}{|c|c|c|c|}
\hline \multicolumn{2}{|c|}{ Chỉ định } & $\mathbf{n}$ & $\%$ \\
\hline \multirow{2}{*}{$\begin{array}{c}\text { Tiền sử mố } \\
\text { sỏi mật }\end{array}$} & 1 lần & 26 & 37,1 \\
\hline & 2 lần & 08 & 11,4 \\
\hline \multirow{2}{*}{$\begin{array}{l}\text { Seo mố cũ } \\
\text { ở tầng trên } \\
\text { ổ bụng }\end{array}$} & Cắt dạ dày & 12 & 17,2 \\
\hline & Mổ khác & 6 & 8,6 \\
\hline \multirow{3}{*}{$\begin{array}{l}\text { Chỉ định } \\
\text { khác }\end{array}$} & $\begin{array}{l}\text { Chống chỉ định } \\
\text { PTNS }\end{array}$ & 8 & 11,4 \\
\hline & $\begin{array}{c}\text { Nội soi mật tụy } \\
\text { thất bại }\end{array}$ & 7 & 10,0 \\
\hline & Chỉ định khác & 3 & 4,3 \\
\hline
\end{tabular}

\section{thuât}

\begin{tabular}{|c|c|c|c|}
\hline $\begin{array}{l}\text { Ngày năm } \\
\text { viện } \\
\text { sau phẫu } \\
\text { thuật }\end{array}$ & $\mathbf{n}$ & $\begin{array}{l}\text { Tỷ lê } \\
(\%)\end{array}$ & $\begin{array}{c}\text { Số ngày } \\
\text { nằm } \\
\text { viện trung } \\
\text { bình }\end{array}$ \\
\hline $6-10$ & 59 & 84,3 & \multirow{3}{*}{$7,91 \pm 2,07$} \\
\hline $11-15$ & 11 & 15,7 & \\
\hline Tống & 70 & 100,0 & \\
\hline
\end{tabular}

Nhận xét: thời gian nằm viện trung bình là 7,9 ngày; ngắn nhất là 6 ngày, dài nhất là 15 ngày

\section{Bảng 3.7. Biến chứng sau mố}

\begin{tabular}{|c|c|c|}
\hline Biến chứng & $\mathbf{n = 7 0}$ & Tỷ lệ (\%) \\
\hline Tụ dịch dưới gan & 4 & 5,7 \\
\hline Nhiềm trùng vết mố & 2 & 2,9 \\
\hline Chảy máu sau mố & 1 & 1,4 \\
\hline Sót sỏi OMC & 0 & 0,0 \\
\hline
\end{tabular}

Nhận xét: Có 4 TH tụ dịch dưới gan với sổ lượng ít, không có TH nào sót sỏi

\section{BÀN LUẬN}


Một số đặc điển nhóm nghiên cứu. Trong số 70 trường hợp sỏi đường mật chính ngoài gan được phẫu thuật có 42 nữ và 28 nam. Tỉ lệ nam/ nữ là 1,5 ; tuổi trung bình là $62 \pm 15,2$. Tuổi thấp nhất là 27; tuổi cao nhất là 82 . Kết quả nghiên cứu của chúng tôi phù hợp với các nghiên cứu về sỏi đường mật chính của các tác giả khác.

Tam chứng Charcot gặp ở 35\% các trường hợp, thấp hơn so với các nghiên cứu khác điều này cho thấy các bệnh nhân của chúng tôi có biểu hiện tắc mật và nhiễm trùng không nặng nề như các nghiên cứu khác. Đây cũng là yếu tố để chúng tôi xét khâu kín ống mât chủ ngay khi phẫu thuật cho các bệnh nhân này; đau hạ sườn phải gặp ở $100 \%$ các trường hợp, là lý do làm cho bệnh nhân đến viện, mức độ đau khác nhau từ âm î đến dữ dội thành cơn. Các nghiên cứu về bệnh sỏi đường mật chính khác cũng có tỉ lệ đau hạ sườn phải cao từ $95 \%$ đến $100 \%$.

Xét nghiệm huyết học cho thấy chỉ có 1 trường hợp có biểu hiện thiếu máu nhe trước mổ, chúng tôi phải tuyền máu sau mổ, Chúng tôi gặp $29 \mathrm{TH}(41,1 \%)$ có bạch cầu trên 10,0G/L trong đó có $6 \mathrm{TH}$ tăng trên $15,0 \mathrm{G} / \mathrm{L}$, tất cả các trường hợp này đều được điều trị nội khoa trước mổ khi kiểm tra lại số lượng bạch cầu trở về mức bình thường mới tiến hành phẫu thuật.

Tỉ lệ SGOT tăng là 40,0\%, SGPT là 44,3\% và bilirubin trong máu tăng là $70 \%$. Trong bệnh lý sỏi đường mật chính, sỏi gây tắc mật làm tăng bilirubin máu, thường là tăng bilirubin trực tiếp, tỉ lệ bilirubin máu thường tăng cao hơn so với tỉ lệ vàng da trên lâm sàng vì vàng da chỉ xuất hiện khi bilirubin tăng cao ở mức độ nhất định. Tình trạng tắc mật cũng sẽ gây hủy hoại tế bào gan làm men gan tăng tuy vậy giá trị cao nhất của SGOT là 239 và SGPT là 258, có 12 trường hợp có Amylase tăng cao nhưng không có trường hợp nào có biểu hiện viêm tụy cấp trên lâm sàng. Các trường hợp này đều được điêu trị nội khoa trước mổ khi các chỉ số trong giới hạn cho phép mới tiến hành phẫu thuật

Bàn về chỉ định, kết quả của kỹ thuật. Phẫu thuật mở bụng, mở ống mật chủ lấy sỏi dẫn lưu Kehr có hoặc không kèm theo cắt túi mật là phẫu thuật kinh điển vẫn được áp dụng. Hiện nay phẫu thuật nội soi điều trị sỏi đường mật chính đã được áp dụng rộng rãi với nhiều ưu điểm: ít đau sau mổ, phục hồi nhanh, thời gian nằm viện ngắn, thẩm mỹ cao, giảm nguy cơ viêm dính về sau. Tuy nhiên không phải tất cả các trường hợp đều có thể thực hiện được bằng phẫu thuật nội soi, không ít trường hợp có chống chỉ định phẫu thuật nội soi và cũng không phải tất cả các cơ sở ngoại khoa các phẫu thuật viên đều có thể thực hiện được phẫu thuật nội soi sỏi đường mật chính. Nội soi mật tụy ngược dòng để điều trị sỏi ống mật chủ đơn thuần được ưu tiên lựa chọn ở nhiều bênh viên vì bênh nhân không phải gây mê, tỉ lệ thành công cao, hồi phục sớm. Nhưng phương pháp này cũng có những nhược điểm và có thể có những biến chứng nhất định như nhiễm trùng đường mật ngược dòng, chảy máu đường mật, thủng tá tràng, viêm tụy cấp... và rất khó thực hiện khi sỏi có kích thước trên $2 \mathrm{~cm}$.

Như vậy trong những trường hợp không phẫu thuật nội soi được và không lấy sỏi qua nội soi mật tụy ngược dòng được thì phẫu thuật mở bụng, mở ống mật chủ lây sỏi là cần thiết. Nghiên cứu của chúng tôi ở 70 trường hợp thì có $34 \mathrm{TH}(48,5 \%)$ có tiền sử mổ sỏi mật, $18 \mathrm{TH}$ $(25,8 \%)$ có tiền sử mổ tầng trên ổ bụng, $8 \mathrm{TH}$ (11,4\%0 có chống chỉ định PTNS, 7 TH nội soi mật tụy ngược dòng thất bại (bảng 3.5).

Khâu kín ống mật chủ sau khi lấy sỏi có hoặc không kèm theo cắt túi mật được chúng tôi thực hiện ở tất cả các trường hợp trong nghiên cứu này. Tiêu chuẩn để chúng tôi quyết định khâu kín $\mathrm{OMC}$ là: Đã lấy hết sỏi đường mật chính ngoài gan; không có sỏi trong gan; dịch mật trong sạch; cơ Oddi thông tốt. Qua nghiên cứu chúng tôi thấy rằng để đảm bảo các tiêu chuẩn này thì cần đánh giá và chuẩn bị bệnh nhân trước mổ thật tốt, trong mổ cần thận trọng kiểm soát sạch sỏi và lưu thông cơ Oddi. Thực vậy tất cả các bệnh nhân trong nghiên cứu của chúng tôi đều được chụp cộng hưởng từ dựng hình đường mật trước mổ xác định không có sỏi trong gan, không có hẹp đường mật (bảng 3.4); Các trường hợp có nhiêm khuẩn đường mật đều phải được điều trị ổn định trước khi phẩu thuật; Phẫu thuật được thực hiện bới các phẫu thuật viên tiêu hóa, gan mật có kinh nghiệm. Như vậy mố có chuấn bị là điều kiện cần thiết để khẩu kín OMC ngay sau khi lấy sỏi.

Khâu kín OMC ngay thường không khó khăn khi mổ mật lần đầu vì ổ bụng không viêm dính, $\mathrm{OMC}$ giãn và ít viêm dày. Trong nghiên cứu này chúng tôi đã khâu kín OMC cho $26 \mathrm{TH}(37,1)$ đã mổ mật 1 lần, $8 \mathrm{TH}(11,4 \%)$ mổ mật 2 lân, 12 TH $(17,2 \%)$ đã cắt dạ dày đều cho kết quả tốt. Như vậy tiền sử mổ mật hay những phẫu thuật ở tầng trên ổ bụng không phải là một chống chỉ định khâu kín OMC ngay sau khi lấy sỏi.

Văn Tần thực hiện và báo cáo kỹ thuật mở OMC không đặt dẫn lưu tại Việt Nam năm 1999 [3]. Tác giả cho rằng không nển áp dụng thường 
quy, chỉ nên thực hiện khâu kín OMC khi: Tình trạng đường mât viêm nhẹ, dịch mật trong; lấy hểt sỏi đoạn dưới gây tắc mật; cớ vòng Oddi thông tốt; phấu thuật viên có kinh nghiệm mổ đường mật. Kết luận này cũng được đưa ra trong nghiên cứu của Nguyển Ngọc Bích; Nguyễn Hoàng Bắc [1], [2].

Kết quả của phẫu thuât trong nghiên cứu của chúng tôi cho thấy thời gian nằm viện trung bình là $7,91 \pm 2,07$, ngắn nhất là 6 ngày, dài nhất là 15 ngày. Kết quả này phù hợp với nghiên cứu của Văn Tần có thời gian nẳm viện sau mổ ở nhóm khâu kín $\mathrm{OMC}$ là 8,63 ngày ngắn hơn nhóm dẫn lưu Kehr là 13,47 ngày. Theo Zhiyuan Tu, Jiadongli và cộng sự thời gian nằm viện trung bình sau khi khâu kín $\mathrm{OMC}$ là 8,72 ngày. Tỉ lệ biến chứng chung trong nghiên cứu của chúng tôi là $10 \%$ trong đó biến chứng hay gặp nhất là tụ dịch dưới gan $4 \mathrm{TH}(5,7 \%)$, $2 \mathrm{TH}$ nhiếm trùng vết mổ, 1 TH chảy máu sau mổ nhưng tất cả các trường hợp đều được điều trị nội khoa không cần mổ lại trường hợp nào. Các nghiên cứu trong và ngoài nước về khâu kín OMC ngay sau khi lấy sỏi đều có tỉ lệ biến chứng từ 2 đến $12 \%$ [1], [2], [3].

I.Ahmed, C. Pradhan nghiên cứu trên $67 \mathrm{TH}$ phẫu thuật khâu kín $\mathrm{OMC}$ sau khi lấy sỏi thấy tỉ lệ biến chứng là $8,9 \%$, thấp hơn so với nhóm dẫn lưu Kehr, đồng thời cho rằng đây là phương pháp an toàn và hiệu quả, chỉ định tốt cho các trường hợp sỏi đường mật chính ngoài gan [4].

Trong nghiên cứu chúng tôi tiến hành siêu âm kiển tra lại đường mật và ổ bụng cho tất cả các bệnh nhân trước khi ra viện và hẹn kiểm tra lại sau mổ 1 đến 3 tháng, kết quả siêu âm không gặp trường hợp nào sót sỏi OMC sau mổ. Cũng như các tác giả khác chúng tôi cho rằng sẽ không có khó khăn phức tạp để lấy hết sỏi OMC với các phẫu thuật viên tiêu hóa, gan mật có kinh nghiệm [3], [5].

\section{KẾT LUẬN}

Phẫu thuật khâu kín ống mật chủ ngay sau khi lấy sỏi để điều trị sỏi đường mật chính ngoài gan an toàn và hiệu guả, chỉ định tốt cho các trường hợp không phâuu thuật nội soi được và không lấy sỏi qua nội soi mật tụy ngược dòng được. Khâu kín ống mật chủ sau khi đã lấy hết sỏi đường mật chính ngoài gan, không có sỏi trong gan, dịch mật trong, Oddi thông tốt.

\section{TÀI LIÊU THAM KHẢO}

1. Nguyễn Hoàng Bắc (2006), " Khâu kín ống mật chủ thì đầu trong phẫu thuâtt để điều tri sỏi đường mật chính qua ngả nội soi ổ bụng" Y học TP Hố Chí Minh, 10 (3), tr 137 - 141.

2. Nguyển Ngọc Bích, Trân Mạnh Hùng (2011), " Phâu thuật nội soi lấy sỏi đường mật chính tại khoa Ngoại Bệnh viện Bạch mai" Tạp chí Y - Dược học Quân sự , vol 36́, tr $56-61$.

3. Vằn Tân, Hồ Huỳnh Long, Nguyễn Cao Cương, Lế Hữu Phước (1999), "Mở ống mật chủ không đặt ống dẫn lưu", Báo cáo khoa học, Đại hội hội ngoại khoa toàn quốc lần thứ $X, \operatorname{tr} 56$ - 62 .

4. Ahmed I, Pradhan. C, Beckingham. I. J, et al (2008), "Is a T - tube after common bile duct exploration", World J Surg, 33 (7), pp1485 - 1488.

5. Dong. D. R, Seo W. H, Kang. S. H et al (2003), " Comparision of clinical characteriatics between primary closure of common bile duct and $\mathrm{T}-$ tube drainage after choledochotomy", Korean Journal of HBP Surg, 7(1), pp 119 - 123

6. Zhiyuan Tu, Jiadong li, Hailin Xin et al (1999), " Primary choledochorrhaphy after common bile duct exploration", Diges Surg, (16), pp $137-139$.

\section{ĐÁNH GIÁ HIÊUU QUẢ TRỢ’ THI NHÌN GẦN TRÊN NGƯỜ'I KHIẾM THI VIỆT NAM}

\section{TÓM TẮT}

Mục tiêu: Đánh giá hiệu quả của các phương tiên trơ thi nhìn gần trên người khiếm thị Việt nam. Đối tượng: Nghiên cứu được thực hiện trên 886 người khiếm thị đến khám tại Phòng phục hồi chức năng

\section{${ }^{1}$ Bệnh viện Mắt Trung Ương}

Chịu trách nhiệm chính: Nguyễn Thị Thu Hiền

Email: thuhienvnio@gmail.com

Ngày nhận bài: 4.01.2021

Ngày phản biện khoa học: 26.2.2021

Ngày duyệt bài: 9.3.2021

\section{Nguyễn Thị Thu Hiền ${ }^{1}$, Trần Phương Anh ${ }^{1}$}

khiếm thi của Bênh viên Mắt Trunq ươnq tronq 3 năm từ 2013 đến 2016. Phương pháp nghiên cứu: mô tả cắt ngang. Kết quả: trong số 478 trẻ khiếm thị có 29.3\% đã được chỉ định sử dụng phương tiện trợ thị nhìn gần, trong đó kính gọng phóng đại được sử dụng nhiều nhất (56.4\%). Công suất kính phóng đại từ +6.00 đến $+38.00 \mathrm{D}$. So với trước trơ thi, thi lực nhìn gần sau trợ thị được cải thiện đáng kể $1.14 \pm 0.28 \mathrm{M}$ $(\mathrm{p}<0.05)$, khoảng cách đọc cải thiện nhiều nhất với máy video phóng đại cầm tay. Trong số 408 người khiếm thị tuổi trưởng thành có $46.3 \%$ đã được chỉ định sử dụng phương tiện trợ thị nhìn gần, trong đó kính lúp cầm tay được sử dụng nhiều nhất (35.4\%). Công suất kính phóng đại từ +4.00 đến $+28.00 \mathrm{D}$. So 